\title{
Device-measured physical activity, sedentary behaviour and cardiometabolic health and fitness across occupational groups: a systematic review and meta- analysis
}

Stephanie A. Prince ${ }^{1,2^{*}}$ D, Cara G. Elliott ${ }^{1}$, Kyle Scott ${ }^{1,3}$, Sarah Visintini ${ }^{4}$ and Jennifer L. Reed ${ }^{1,3,5}$

\begin{abstract}
Background: With approximately 8 hours of one's waking day spent at work, occupational tasks and environments are important influencers on an individual's physical activity (PA) and sedentary behaviours. Little research has compared device-measured physical activity, sedentary behaviour and cardiometabolic outcomes between occupational groups.

Objective: To compare device-measured movement (sedentary time [ST], light intensity physical activity [LPA], moderate-to-vigorous intensity physical activity [MVPA], and steps) across occupations. The secondary objective was to examine whether cardiometabolic and fitness outcomes differed by occupation.

Methods: Five bibliographic databases were searched to identify all studies which included working age, employed adults from high-income countries, and reported on device-measured movement within occupations. Risk of bias within and across studies was assessed. Results were synthesized using meta-analyses and narrative syntheses.

Results: The review includes 132 unique studies with data from 15,619 participants. Working adults spent 60\% of their working and waking time engaged in sedentary behaviour; a very small proportion $(\sim 4 \%)$ of the day included MVPA. On average, workers accumulated 8124 steps/day. Office and call center workers' steps/day were among the lowest, while those of postal delivery workers were highest. Office workers had the greatest ST and the lowest time in LPA both at work and during wakeful time. However, office workers had the greatest minutes sent in MVPA during wakeful hours. Laborers had the lowest ST and spent a significantly greater proportion of their work time in LPA and MVPA. Healthcare and protective services workers had higher levels of LPA at work compared to other occupations. Workers in driving-based occupations tended to have a higher body mass index and blood pressure.
\end{abstract}

Conclusion: This review identifies that occupational and wakeful time PA and ST differed between occupations. Future studies are needed to assess whether patterns differ by age and sex, describe leisure-time movement and movement patterns, and the relationship with cardiometabolic health.

Systematic review registration: PROSPERO CRD42017070448.

Keywords: Occupation, Workplace, Motor activity, Sedentary behaviour, Systematic review

\footnotetext{
* Correspondence: sprinceware@ottawaheart.ca

'Division of Cardiac Prevention and Rehabilitation, University of Ottawa Heart

Institute, 40 Ruskin Street, Ottawa, Ontario K1Y 4W7, Canada

${ }^{2}$ Centre for Surveillance and Applied Research, Public Health Agency of

Canada, Ottawa, Canada

Full list of author information is available at the end of the article
}

(c) The Author(s). 2019 Open Access This article is distributed under the terms of the Creative Commons Attribution 4.0 International License (http://creativecommons.org/licenses/by/4.0/), which permits unrestricted use, distribution, and reproduction in any medium, provided you give appropriate credit to the original author(s) and the source, provide a link to the Creative Commons license, and indicate if changes were made. The Creative Commons Public Domain Dedication waiver (http://creativecommons.org/publicdomain/zero/1.0/) applies to the data made available in this article, unless otherwise stated. 


\section{Introduction}

It is well established that regular physical activity (PA) prevents several chronic conditions (e.g. cardiovascular disease, diabetes, cancer, hypertension, obesity, depression, and osteoporosis) and premature all-cause mortality $[1,2]$. The World Health Organization recommends that adults accumulate a minimum of $150 \mathrm{~min}$ of moderate-to-vigorous intensity PA (MVPA) per week for good health [3]. Reported adherence to these guidelines in high-income countries remains low (36.8\%) [4] and the prevalence of inactivity is more than double that in low income countries [5]. Independent of MVPA, there is strong evidence that time spent in sedentary activities (i.e. sitting, reclining, lying down while awake) [6] increases one's risk for cardiometabolic diseases, cancers, depression, and premature death [7-10]. Much of the evidence looking at the relationships between PA, sedentary behaviour and health outcomes has focused on behaviours that occur outside of work hours (e.g. recreational PA, TV or leisure-time screen use) [10, 11].

In the landmark London Transport Workers Study, Morris et al. found that men who worked more physically active jobs (i.e. conductors) had a lower incidence of heart disease compared to those with inactive jobs (i.e. drivers) [12]. Although this study was published more than 50 years ago, the relationship between movement behaviours and health outcomes across occupations remains poorly understood. The "physical activity paradox" suggests that PA undertaken at work differs in quality, quantity and health effects than PA performed during leisure-time [13]. For example, occupational PA carried out at lower intensities may not elicit substantial improvements in cardiorespiratory fitness, such as in the case of nurses who have been shown to spend a large proportion of their wakeful time in light intensity PA (LPA) [14]. Recent systematic review evidence also suggests that higher levels of occupational PA (even while controlling for leisure-time MVPA) are associated with an increased risk in premature mortality in men [15]. It is important to build on past research to understand the intensities of PA at which workers engage both within and outside of working hours and the associations with cardiometabolic health.

With approximately 8 hours of one's waking day spent at work [16], occupational tasks and environments can heavily influence PA and sedentary time (ST). Occupational PA and ST are broadly defined as the amount of these behaviours accumulated while at work (typically within an 8-h timeframe), whereas leisure-time PA or ST occurs outside of work hours [17]. In the only known systematic review examining occupation and leisure-time PA, Kirk et al. found that white-collar workers accumulated higher amounts of leisure-time PA than blue-collar workers, and occupations with low occupational PA and long work hours were associated with lower leisure-time PA [18]. However, research has shown that individuals are more sedentary at work than during leisure-time, irrespective of occupation type [19]. Beyond white- vs. blue-collar classifications, little research has compared PA levels (i.e. ST, LPA, MVPA) and cardiometabolic and fitness outcomes between occupational groups. Identifying the specific occupations that enable higher rates of inactivity can inform workplace and lifestyle interventions aimed at improving workers' PA levels and health status.

Most of the research examining occupational PA has been measured using self-report tools (e.g. questionnaires) [20], introducing considerable measurement errors (i.e. social desirability, recall bias, poor validity) $[21,22]$. It is likely that individuals misperceive some of their occupational PA as MVPA when in fact, it is spent at lower intensities [23]. Activity monitors such as accelerometers, inclinometers, and pedometers have been validated for measuring ST (including posture in the case of inclinometers), steps, and PA of varying intensity, bouts, and duration [24, 25]. These devices allow movement to be continuously and more precisely monitored, thus effectively studied in many occupational environments.

No rigorous systematic investigations have examined device-measured PA across occupations. With higher income countries experiencing a transition towards more sedentary occupations compared to lower income countries, it is important to understand the PA levels experienced by these workers. Therefore, the primary objective of this systematic review was, to summarize and compare device-measured PA across occupations in adults from high-income countries. This includes step counts, ST, and, time spent in LPA, moderate intensity PA (MPA), vigorous intensity PA (VPA) and MVPA. The secondary objective was to examine whether cardiometabolic and fitness outcomes differ by occupation.

\section{Methods}

The review was prospectively registered with PROSPERO (\#CRD42017070448).

\section{Study inclusion criteria \\ Population}

Working age, employed adults (mean age $=18-65$ years) from high-income countries [26].

\section{Exposure}

PA and ST were examined across occupation groups. Eligible occupations included in the meta-analyses were either specific occupations described within individual studies (e.g. nurses, office workers, postal workers) or occupational groups, which were identified a priori by the authors based on similar occupational task characteristics. Occupational groups included: (1) drivers (bus, 
lorry, taxi, transit, truck); (2) laborers (agriculture, cleaners, construction workers, dry cleaners, farmers, freight mechanics); (3) protective services (army, firefighters, national guard, paramedics, police); (4) factory workers (extractive and precision, fabric machine operators, meat processing); (5) call center workers; (6) academics (researchers, scientists, lecturers); (7) school teachers; (8) healthcare (diagnosticians, nurses, nurses' aides, physicians, physiotherapists); (9) office workers (administrative, civil servants, postal workers in offices, professionals/managers, records, secretaries, software); (10) customer service and hospitality (cooks, customer service, retail, servers); and, (11) postal delivery workers.

\section{Outcomes}

The primary outcome was device-measured (e.g. accelerometers, inclinometers, pedometers) physical behaviours within occupation groups, including: ST; LPA; MPA; VPA; and, MVPA. This included activity at work, leisure-time and during wakeful time. The secondary outcomes were cardiometabolic health indicators (selfreport and objective measures), including: body mass index (BMI); waist circumference; waist-to-hip ratio (WHR); body fat percentage; resting systolic blood pressure (SBP) and diastolic blood pressure (DBP); total cholesterol; high density lipoprotein (HDL), low density lipoprotein (LDL); triglycerides; total cholesterol-to-HDL ratio (TC:HDL); blood glucose; HbA1c; HOMA-IR; and, fitness $\left(\dot{\mathrm{VO}}_{2}\right.$ peak). All units for cardiometabolic outcomes were standardized to the same units.

\section{Study designs}

Observational (e.g. cross-sectional, prospective cohort, retrospective cohort) and experimental (e.g. baseline data from randomized controlled trials or quasi-experimental trials) studies were included.

\section{Publication status and language}

Both published (peer-reviewed) and unpublished grey literature (e.g. abstracts) were eligible. No language restrictions were imposed on the search, but only papers published in English or French were included due to translation limitations.

\section{Search strategy}

The search strategy was created by a medical librarian (SV) in discussion with the team (SAP, JLR, CGE). The search was first created in MEDLINE using a combination of index terms and keywords related to the workplace, PA, and device measurement tools. The search strategy was then peer-reviewed by a second medical librarian (NA). Once the search was finalized (see Additional file 1: Table S1 for MEDLINE search strategy), it was translated to the other bibliographic databases.
Searches were initially conducted from database inception to July 31, 2017 and then updated to include papers indexed up to and including December 12, 2018 in MEDLINE (Ovid, MEDLINE(R) Epub Ahead of Print, In-Process \& Other Non-Indexed Citations, MEDLINE(R) Daily and MEDLINE(R)), EMBASE (Ovid, Embase Classic + Embase), CINAHL (EBSCO), SPORTDiscus (EBSCO), and Dissertations \& Theses Global (Proquest). Search results were exported to EndNote X7 (Thompson Reuters, San Francisco, CA, USA) and duplicates removed through manual inspection using the EndNote duplicate identification function.

\section{Selection of studies}

Following the initial search, titles and abstracts were exported from EndNote X7 into Microsoft Excel for screening. During the updated search the titles and abstracts were exported into Covidence software (Veritas Health Innovation, Melbourne, Australia). Two reviewers independently reviewed all titles and abstracts (SAP, JLR, CGE) and full texts (SAP, JLR, CGE, KS). A third reviewer was consulted if disagreements occurred. Reviewers were not blinded to the authors of the studies.

\section{Data extraction and analysis}

Data extraction was completed by one reviewer and verified by a second. Information extracted included: publication details; participant characteristics; occupation; sample size analyzed; study design; PA intensity and cardiometabolic and fitness indicators examined; device; units of measurement; and, quantity of the movement intensity (e.g. minutes/day, proportion of wear time) and cardiometabolic indicators across occupational groups.

A narrative synthesis, including summary tables, was used to examine PA and sedentary behaviors and cardiometabolic outcomes across all studies and assess overall trends. Outcomes with sufficient number of studies per outcome per occupation group ( $\geq 3$ studies/group) were compared using random effects meta-analyses to provide a summary measure of movement intensity (e.g. minutes/day of ST) overall and per each occupational sub-group with variance not assumed to be common among subgroups. Forest plots and meta-analyses were created using Comprehensive Meta Analysis Version 3 (Englewood, NJ, USA) to compare quantities of PA intensities, ST and cardiometabolic outcomes (in same units) and 95\% confidence intervals (CIs). Sitting and ST were combined as a single outcome. Pairwise comparisons between groups were performed using a Microsoft Excel sheet supplied by Comprehensive Meta Analysis. Publication bias was conducted using Egger's two-tailed test (when the number of studies was $\geq 10$ ) whereby $p<0.10$ indicated the possibility of bias [27]. 


\section{Risk of bias}

We assessed the risk of bias of the individual studies using a modified version (observational studies) [28] of the Cochrane Collaboration's Tool for Assessing Risk of Bias. Risk of bias graphs were created using Review Manager Version 5.3 (The Nordic Cochrane Centre, The Cochrane Collaboration, Copenhagen). Studies were assessed for potential biases including: selection bias (sampling methods); performance bias (measurement of exposure); attrition bias (incomplete follow-up $+>10 \%$ missing data), selective reporting bias (selective/incomplete reporting, rated high if secondary data analyses); and, other possible sources of bias (i.e. self-reported SB and not controlling for confounders). Risk of bias assessments were carried out by one assessor and verified by a second.

\section{Results}

\section{Study characteristics}

Figure 1 provides a detailed flow diagram of the literature search and screening process. Of the 5597 originally identified non-duplicate publications, 132 unique studies $[14,29-160]$ met the eligibility criteria. The review includes data from 15,619 participants. Study characteristics are presented in Additional file 2: Table S2. The included studies were published from 1983 to 2018. The countries with the most studies included Australia (27\%) and the Unites States (24\%). Most (69\%) were from smaller studies $(N<100$ participants). The majority reported on office-based/desk-based occupations (referred henceforth as office workers). Older studies tended to use pedometers and early generation accelerometers, while more recent studies used newer accelerometers and inclinometers. Accelerometers were the most used devices $(N=70$ studies) followed by inclinometers $(N=$ 41 studies) and pedometers ( $N=30$ studies). Steps/day was the most reported behaviour outcome.

\section{Risk of bias}

Risk of bias results are summarized in Fig. 2. More than half of the studies had a risk of selection bias largely due to convenience samples. Approximately $20 \%$ had no description of how the occupational group was defined (included no clear inclusion criteria; poor selection bias) and occupation definitions were unclear in an additional $\sim 30 \%$ (performance bias). Most of the studies had a low risk of detection bias as most used validated cut-points to define movement intensity (if studies used an unsealed device they were rated as high). Just under $50 \%$ of the studies had a high or unclear risk of attrition bias; largely a result of having $\geq 10 \%$ missing data. Most studies had a low risk of selective reporting bias; most reported on all available data. Finally, most had a low risk of 'other bias' as they used objective measures of cardiometabolic outcomes.

\section{Physical behaviour outcomes}

A summary of physical behaviour outcomes across occupational groups is shown in Additional file 3: Table S3. All meta-analyses and funnel plots for behaviour outcomes are available in Additional file 4: Figures S1-S6.

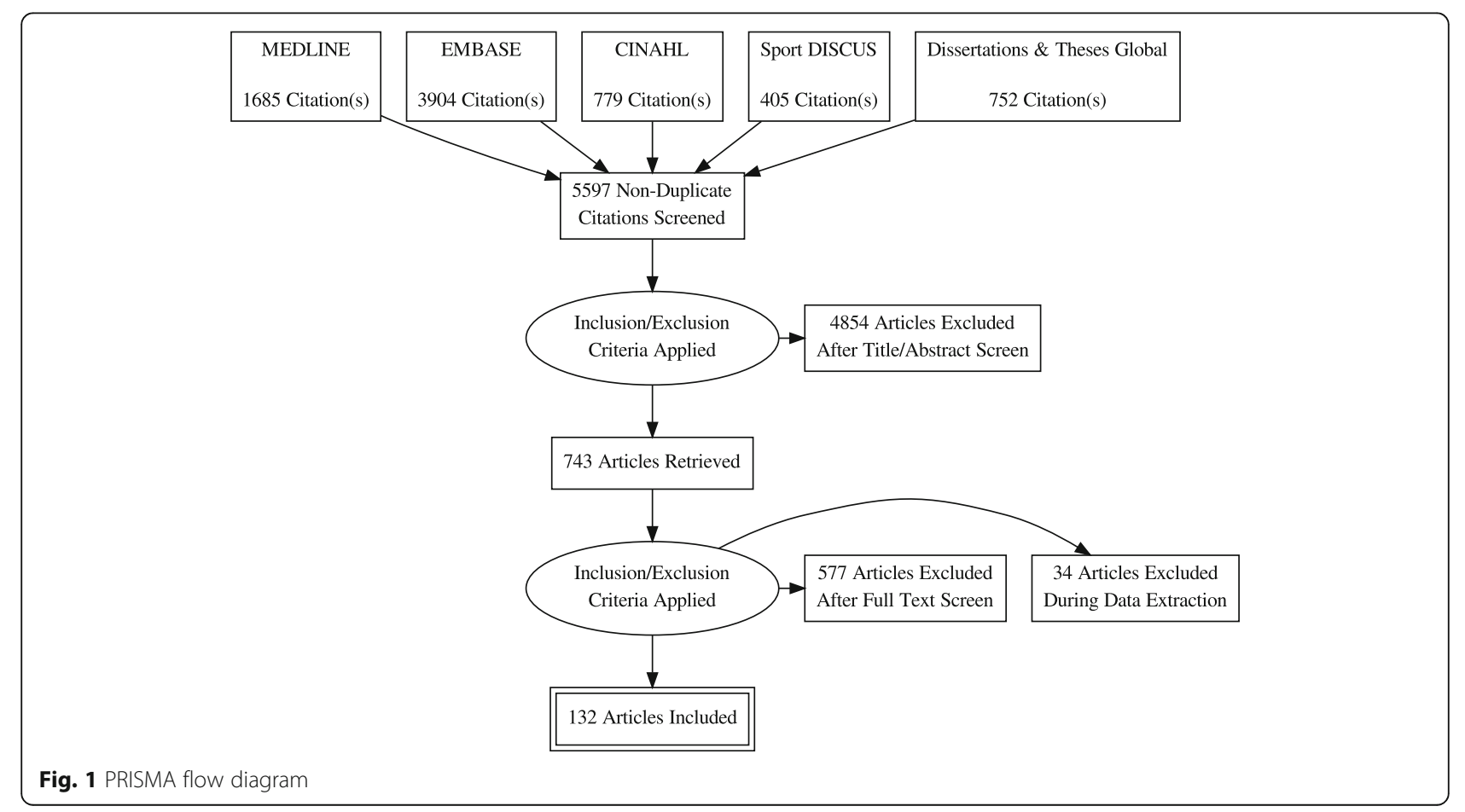




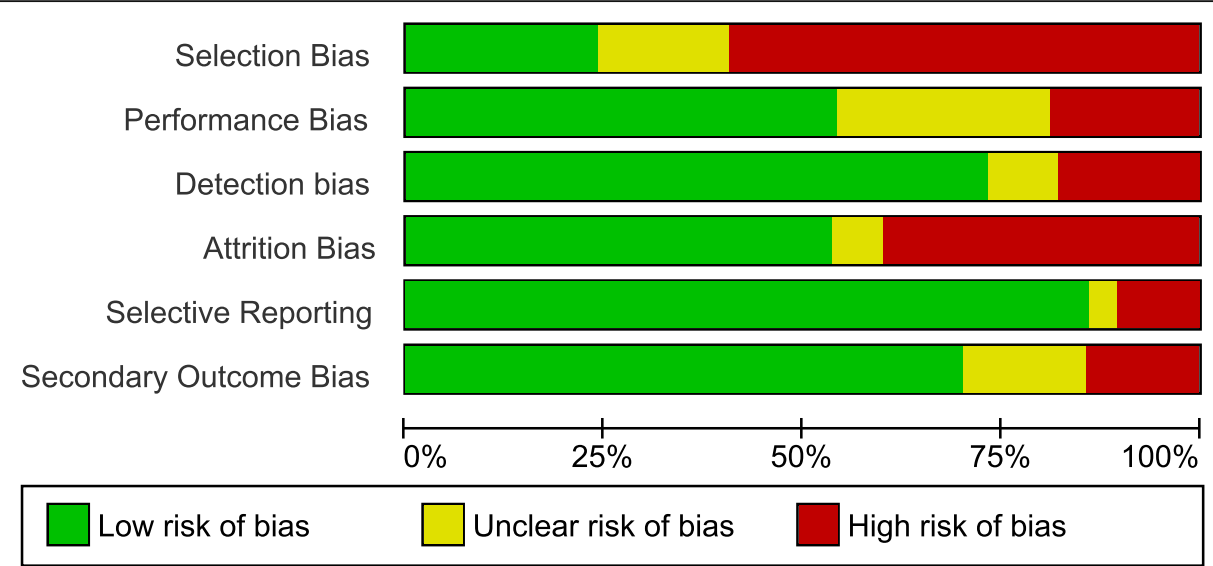

Fig. 2 Summary of risk of bias scores

\section{Sedentary time (ST)}

A meta-analysis of the percentage of ST found that, on average, $60.0 \%$ (95\% CI: 54.2-65.7\%, $\mathrm{I}^{2}=49 \%$, Egger's $p=0.0399)$ of time at work and $58.8 \%$ (95\% CI: $56.7-$ $59.8 \%, \mathrm{I}^{2}=58 \%$, Egger's $\left.p=0.3240\right)$ of all workers' wakeful time was spent being sedentary (Fig. 3a). The proportion of ST was significantly higher in office workers than all other occupations both at work (72.5\% vs. $49.7 \%, Z=3.9919, p=0.0001)$ and during wakeful time $(66.1 \%$ vs. $55.9 \%, \mathrm{Z}=6.9970, p=0.0000)$ (Additional file 4: Figure S1c, e, j, l). Office workers appeared to spend a lower amount of their non-work time in ST; $58.5 \%$ (95\% CI: $55.5-61.6 \%, N=4)$ of their non-work days (including weekends) was spent sedentary (Additional file 4: Figure S1ff). Daily ST in office workers with access to sit-stand desks did not appear different from those without (qualitative assessment). Laborers' proportion of ST was significantly lower than all other workers during wakeful time (46.9\% vs. 59.6\%, $Z=7.7113, \quad p=0.0000$ ) (Additional file 4: Figure S1m-n) and appeared lower during work hours (qualitative assessment). Healthcare workers' proportion of wakeful ST was significantly lower than all other workers $(54.3 \%$ vs. $59.2 \%, \mathrm{Z}=3.2856$, $p=0.001$ ) (Additional file 4: Figure S1p-q).

On average, workers spent $312.1 \mathrm{~min} /$ day at work sedentary (95\% CI: 242.2-381.9, $\mathrm{I}^{2}=28 \%$, Egger's $p=$ 0.00003 ) and $565.8 \mathrm{~min} /$ day sedentary (95\% CI: $510.4-$ $620.8, \mathrm{I}^{2}=0 \%$, Egger's $\left.p=0.00037\right)$. No significant differences were found between occupational groups (Fig. 3b). In general, occupations that largely involve sitting (i.e. drivers, office workers, call center) engaged in greater amounts of ST at work than those in more active occupations (i.e. laborers, healthcare, protective services). There was evidence of publication bias across all measures of ST. Office workers were found to spend 593.1 $\mathrm{min} /$ day (95\% CI: 541.2-645.0, $N=5$ ) sedentary on their non-workdays/weekends (Additional file 4: Figure S1dd), which appeared similar to their ST on workdays (qualitative assessment).

\section{Light intensity physical activity (LPA)}

A meta-analysis of the percentage of time spent in LPA identified that, on average, workers spent $24.1 \%$ (95\% CI: $17.9-30.2 \%, \mathrm{I}^{2}=73 \%$, Egger's $\left.p=0.0005\right)$ of their work time and 30.9\% (95\% CI: $29.7-32.1 \%, \mathrm{I}^{2}=77 \%$, Egger's $p=0.9093$ ) (Fig. 3c) of their wakeful time engaged in LPA. Office workers spent a lower proportion of their waking hours $(23.0 \%$ vs. $32.3 \%, \mathrm{Z}=3.5769, p=0.0003)$ and work time ( $13.2 \%$ vs. $28.3 \%, \mathrm{Z}=2.4714, p=0.0135)$ in LPA when compared to all other workers (Additional file 4: Figure S2c, d, g, h). Laborers spent a greater proportion of their waking hours in LPA compared to all other workers (41.0\% vs. $30.0 \%, \mathrm{Z}=2.0767, p=0.0378$ ) (Additional file 4: Figure S2k-1). Healthcare workers spent a significantly higher proportion of their wakeful hours engaged in LPA compared to all other workers $(39.5 \%$ vs. $30.0 \%, \mathrm{Z}=$ 2.0226, $p=0.0431$ ) (Additional file 4: Figure $S 2 \mathrm{i}-\mathrm{j}$ ). Laborers, protective services, and healthcare workers appeared to spend a greater proportion of their work time in LPA compared to desk-based occupations.

On average, workers spent 133.8 (95\% CI: 105.7162.0, $\mathrm{I}^{2}=73 \%$, Egger's $\left.p=0.08696\right)$ and 309.3 (95\% CI: 204.1-414.5, $\mathrm{I}^{2}=47 \%$, Egger's $\left.p=0.05699\right)$ minutes $/$ day at work and during wakeful time in LPA, respectively (Fig. 3d). Office workers spent significantly fewer minutes at work engaged in LPA compared to all other workers (48.0 vs. 223.5, $\mathrm{Z}=4.0153, p=0.0001$ ). Based on our qualitative assessment, it appears that laborers and healthcare workers tended to have higher minutes/day spent in LPA. Call center and office workers tended to have fewer minutes/day of LPA at work, while protective service and healthcare workers had greater minutes/day at work in LPA. 


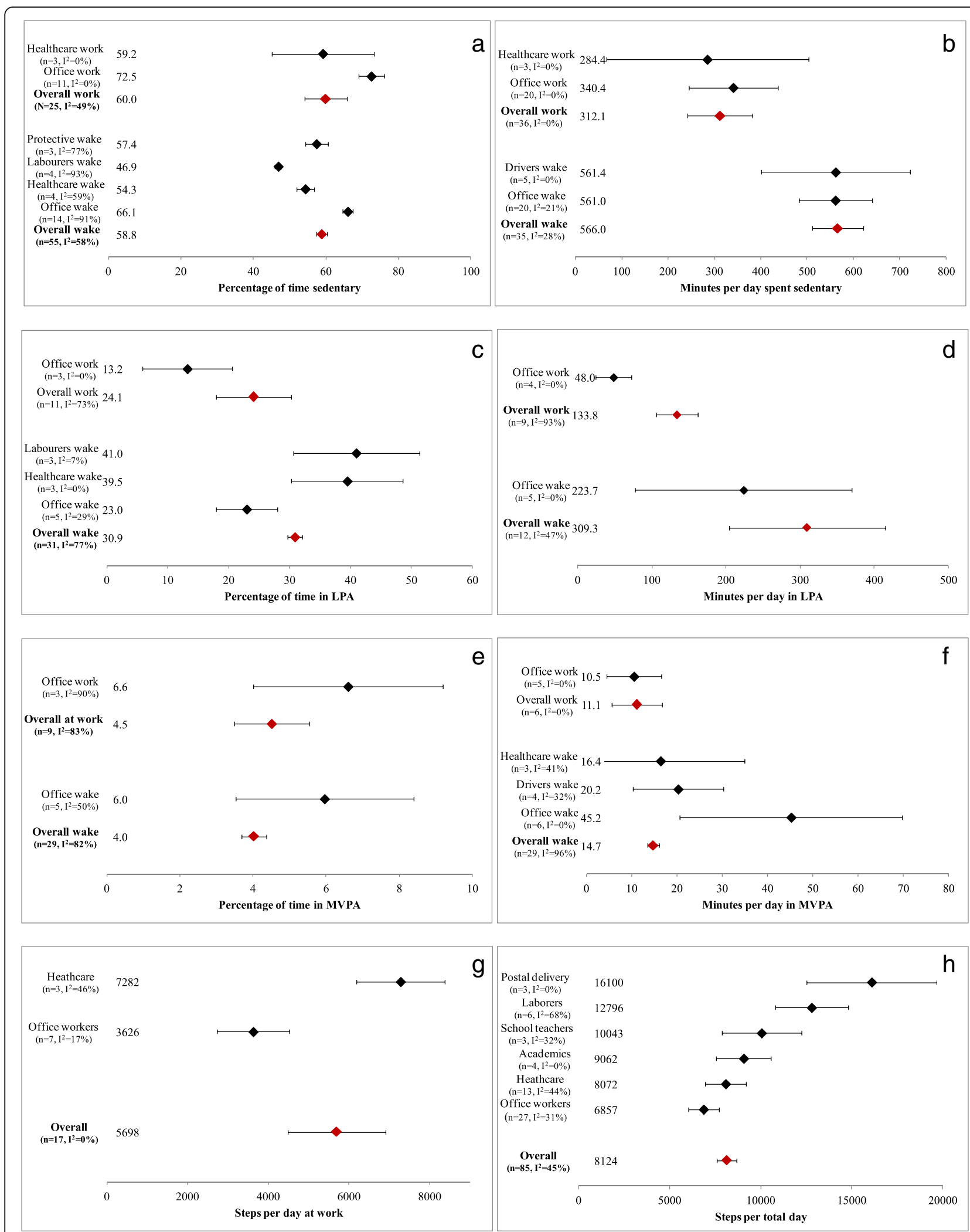

Fig. $\mathbf{3}$ a-h Percentage and minutes of total wake time and time at work spent in sedentary (a and $\mathbf{b}$ ), light- (c and $\mathbf{d}$ ) and moderate-to-vigorous intensity physical activity (e and $\mathbf{f}$ ) and steps at work (g) and during wakeful time (h) overall (red diamonds) and by occupation group (black diamonds). $I^{2}$ - measure of heterogeneity, LPA - light intensity physical activity, MVPA - moderate-to-vigorous intensity physical activity, $\mathrm{n}$ - number of studies 


\section{Moderate-to-vigorous intensity physical activity (MVPA)}

A meta-analysis of the percentage of daily time spent in MVPA identified that, on average, workers spent 4.5\% (95\% CI: $3.5-5.6 \%, \mathrm{I}^{2}=83 \%$, Egger's $p=0.07633$ ) of their work time and $4.0 \%$ (95\% CI: $3.7-4.4 \%, \mathrm{I}^{2}=82 \%$, Egger's $p=$ 0.08545) of their wakeful time in MVPA (Fig. 3e). No significant differences between-occupational groups were identified. However, with the removal of an outlier (office workers) [96], office and call center workers tended to spend a lower proportion of their work time in MVPA compared to other workers. A meta-analysis found that, on average, workers (largely office workers) obtained 11.1 (95\% CI: 5.516.7) minutes at work and 14.7 min per wakeful time $(95 \%$ CI: $13.5-16.0, \mathrm{I}^{2}=96 \%$, Egger's $p=0.00007$ ) in MVPA (Fig. 3f). Office workers engaged in more minutes/day of MVPA compared to other workers (45.2 vs. 11.0, $\mathrm{Z}=2.7224, p=$ 0.0065) (Additional file 4: Figure S3g, i).

A subset of studies reported on MPA and VPA separately. Meta-analytic results showed that workers obtained an average of 43.2 (95\% CI: 31.9-545.5, $\left.\mathrm{I}^{2}=99 \%\right)$ minutes/day and 4.4\% (95\% CI: $\left.3.4-5.3 \%, \mathrm{I}^{2}=86 \%\right)$ at work and 52.6 (95\% CI: 43.4-61.7, $\mathrm{I}^{2}=94 \%$ ) minutes/day and 5.5\% (95\% CI: 3.6$7.3 \%, \mathrm{I}^{2}=91 \%$ ) during wakeful time of MPA (Additional file 4: Figure S4a-h). Office workers engaged in significantly fewer minutes of MPA during wakeful time compared to all other (included laborers, call center workers, healthcare, and athletes) workers (32.2 vs. 82.1, Z = 3.9246, $p=0.0001$ ) (Additional file 4: Figure S4i-j). Our qualitative analyses indicate that laborers and protective service workers tended to have greater wakeful and work-specific time spent in MPA. Workers also engaged in 0.7 (95\% CI: $0.3-1.098)$ minutes/day and 0.4\% (95\% CI: $0.2-0.6 \%)$ while at work and $1.9(95 \% \mathrm{CI}: 0.7-3.1) \mathrm{mi}-$ nutes/day and $0.2 \%$ (95\% CI: $0.1-0.3 \%$ ) during wakeful time in VPA (Additional file 4: Figure S5a-h).

\section{Steps}

Occupational groups that were primarily desk-based accumulated fewer steps than those with more 'active' occupations both during work time and across the day. The meta-analysis of steps taken during work time found that, on average, workers took 5698 steps at work (95\% CI: 4485-6911, $\mathrm{I}^{2}=0 \%$ ) (Fig. 3g). Office workers accumulated significantly fewer steps at work compared to healthcare workers (3626 vs. $7282, \mathrm{Z}=5.0676, p=$ 0.0000 ) and all other workers (3626 vs. $7124, Z=5.0735$, $p=0.0000$ ) (Additional file 4: Figure S6b-d). Laborers appeared to have some of the highest number of steps at work.

A meta-analysis of steps/wakeful hours identified that, on day per day (95\% CI: 7586-8661, I $\left.{ }^{2}=45 \%\right)$ (Fig. 3h). Steps/ day were lowest amongst office workers (6857, 95\% CI: 6023-7692) and highest among postal delivery workers $(16,100$, 95\%CI: 12526-19,674). Office workers had significantly fewer total steps during wakeful time than all other workers (6857 vs. $8745, \mathrm{Z}=3.2677, p=0.0011$ ) (Additional file 4: Figure $\mathrm{f}-\mathrm{g}$ ). Our qualitative assessment suggests that call center workers have some of the lowest total steps/ wakeful time.

\section{Cardiometabolic and fitness outcomes}

A summary of cardiometabolic outcomes across occupational groups is shown in Additional file 5: Table S4. All meta-analyses and funnel plots for cardiometabolic and fitness outcomes are available in Additional file 4: Figures S7-S18.

\section{Body mass index (BMI)}

A meta-analysis of BMI found that workers had an average BMI of $26.5 \mathrm{~kg} / \mathrm{m}^{2}$ (95\% CI: $25.9-27.1, \mathrm{I}^{2}=98 \%$, Egger's $p=0.2176$ ) (Fig. 4b, Additional file 4: Figure S7). Drivers had a significantly higher average BMI than office workers (30.1 vs. $26.5 \mathrm{~kg} / \mathrm{m}^{2}, \mathrm{Z}=2.9060, p=0.0037$ ), office workers with sit-stand desks (30.1 vs. $25.5 \mathrm{~kg} / \mathrm{m}^{2}$, $\mathrm{Z}=2.4322, p=.0150$ ), call center workers (30.1 vs. 25.7 $\left.\mathrm{kg} / \mathrm{m}^{2}, \mathrm{Z}=2.7118, p=0.0067\right)$, and healthcare workers (30.1 vs. $24.7 \mathrm{~kg} / \mathrm{m}^{2}, \mathrm{Z}=4.6298, p=0.0000$ ) (Additional file 4: Figure S7c-j). Qualitatively, BMI tended to be higher among occupations with a greater proportion of men such as protective services (e.g. fire fighters, soldiers), laborers (e.g. construction workers, farmers) and drivers (e.g. taxi, truck drivers).

\section{Waist circumference}

A meta-analysis of waist circumference found that workers had an average waist circumference of $90.2 \mathrm{~cm}$ (95\% CI: 86.4-94.0, $\mathrm{I}^{2}=0 \%$, Egger's $p=0.17461$ ) (Fig. 4b, Additional file 4: Figure S8a-d). No significant differences were found between office workers and healthcare workers. Qualitatively, waist circumference tended to be higher among laborers and drivers.

\section{Waist-to-hip ratio (WHR)}

A small ( $N=6$ [3 office]) meta-analysis (Fig. 4c) found that workers had an average WHR of 0.82 (95\% CI: $0.79-0.85, \mathrm{I}^{2}=0 \%$ ) (Additional file 4: Figure S9a-d). Office workers had a significant higher WHR than all other workers $(0.84$ vs. $0.80, \mathrm{Z}=2.4778, p=0.0132)$ (Additional file 4: Figure S9c-d).

\section{Body fat percentage}

Twelve studies ( 9 office) reported on percentage of body fat. A meta-analysis found that workers had an average body fat percentage of $29.7 \%$ (95\% CI: $27.0-32.5 \%, \mathrm{I}^{2}=$ $7 \%$, Egger's $p=0.01855$ ) (Fig. 4d). Office workers were no different than all other workers $(30.2 \%$ vs. $29.2 \%, Z=$ $0.3, p=0.7489$ ) (Additional file 4: Figure S10c-d). 


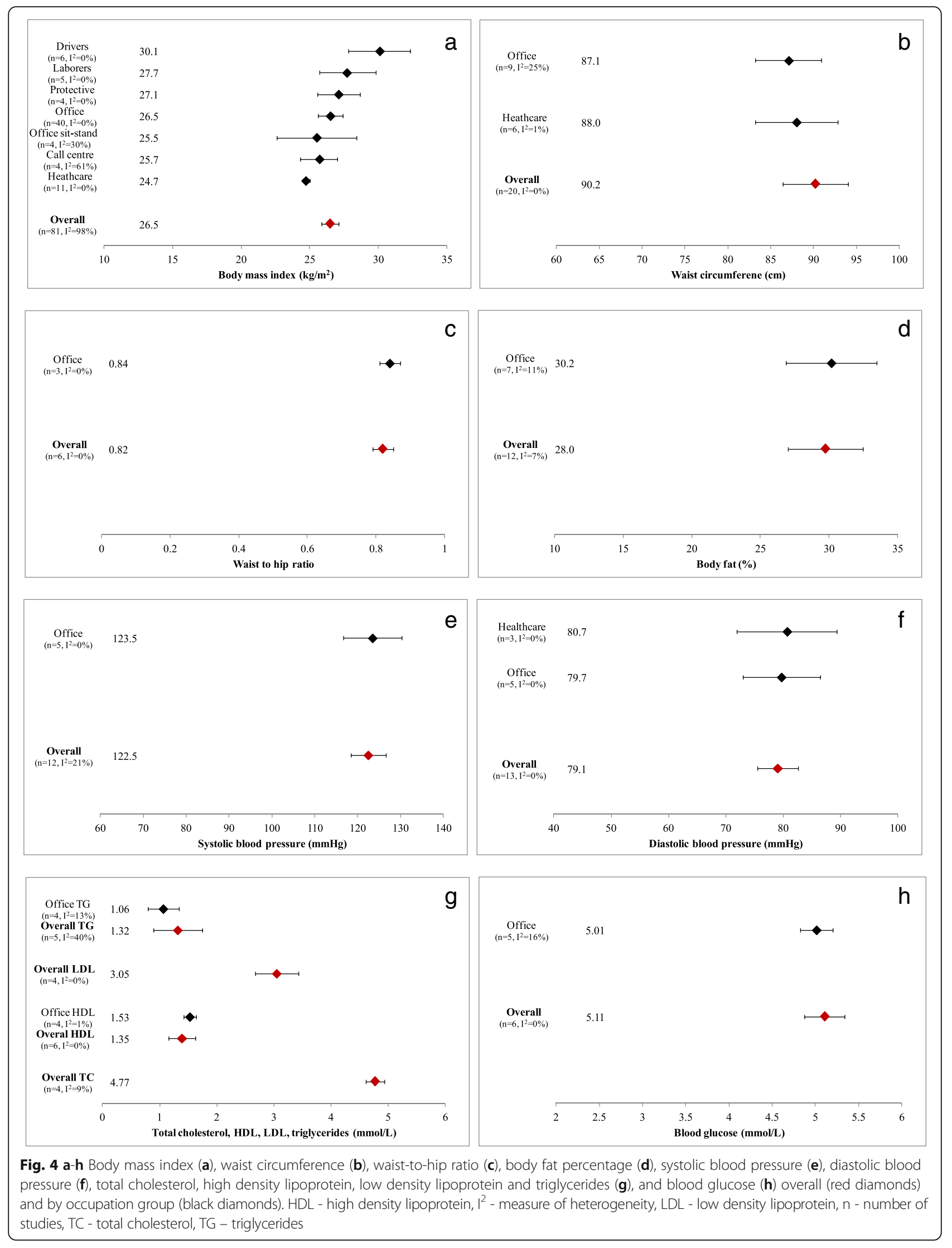




\section{Blood pressure (BP)}

Twelve studies had enough BP data to be included in a meta-analysis. Workers had an average SBP of 122.5 mmHg (95\% CI: $118.4-126.6, \mathrm{I}^{2}=21 \%$, Egger's $p=$ 0.03538 ) (Fig. 4e) and an average DBP of $79.1 \mathrm{mmHg}$ (95\% CI: 75.5-82.7, $\mathrm{I}^{2}=0 \%$, Egger's $p=0.01109$ ) (Fig. 4f). There is evidence of publication bias for these studies (Additional file 4: Figures S11b and S12b). Qualitative assessments indicate that occupations which rely heavily on driving vehicles appeared to have higher BPs and healthcare workers appeared to have lower BPs.

\section{Blood lipids}

Few studies provided sufficient total cholesterol $(N=4$ [3 office]), triglycerides $(N=5$ [4 office]), HDL $(\mathrm{N}=6$ [4 office]), or LDL ( $\mathrm{N}=4$ [2 office]) data to be included in meta-analyses. Workers had an average total cholesterol level of $4.77 \mathrm{mmol} / \mathrm{L}$ (95\% CI: $4.61-4.93, \mathrm{I}^{2}=9 \%$ ), triglycerides of $1.32 \mathrm{mmol} / \mathrm{L}$ (95\% CI: $0.89-1.75, \mathrm{I}^{2}=40 \%$ ); HDL of $1.39 \mathrm{mmol} / \mathrm{L}$ (95\% CI: $1.16-1.63, \mathrm{I}^{2}=0 \%$ ) and, LDL of $3.05 \mathrm{mmol} / \mathrm{L}$ (95\% CI: $\left.2.67-3.43, \mathrm{I}^{2}=0 \%\right)$ (Fig. 4g, Additional file 4: Figures S13a-b, S14a-b, S15a-b, S16a-b).

\section{Blood glucose, HbA1c and HOMA-IR}

A limited number of studies provided adequate data to be included in the blood glucose meta-analyses; five of the six included data from office worker populations. The average blood glucose concentrations across workers were $5.11 \mathrm{mmol} / \mathrm{L}$ (95\% CI: 4.88-5.34, $\mathrm{I}^{2}=0 \%$ ) (Fig. 4h, Additional file 4: Figure S17a-b). Single studies reported on HbA1c, [89] 2-h glucose [31] and HOMA-IR [31].

\section{Peak $\mathrm{VO}_{2}$}

Five studies (three in office workers) reported comparable data for peak $\dot{\mathrm{VO}}_{2}$ and were included in a meta-analysis. Workers exhibited an overall peak $\dot{\mathrm{VO}}_{2}$ of $32.7 \mathrm{~mL} / \mathrm{min} / \mathrm{kg}$ (95\% CI: 30.5-34.9, $\mathrm{I}^{2}=0 \%$ ); there was no statistically significant difference between studies (Additional file 4: Figure S18a-b).

\section{Discussion}

This systematic review examined and compared device-measured PA and ST, and cardiometabolic health and fitness indicators across occupation groups. Working adults spent about $60 \%$ of their working and waking time in sedentary behaviour; a very small proportion $(\sim 4 \%)$ of the day included MVPA. On average, workers fell within the 7000 to 11,000 steps/day range associated with good health [161]. Office and call center workers' steps/day were among the lowest, while labourers and postal delivery workers had the most. We found several occupational group-related differences in levels of ST, LPA and MVPA at work and during wakeful time.
Occupations that were desk-based (i.e. office workers) had the highest ST and the lowest number of steps, LPA (work and wakeful time) and MVPA (work). They did however, have more daily minutes of MVPA compared to all other workers. Laborers had the lowest ST and spent a significantly greater proportion of their work time in LPA and MVPA. Healthcare and protective services workers had higher levels of LPA at work (and wakeful time in healthcare) compared to other workers. Workers in driving-based occupations tended to have higher BMIs and BPs. While office workers had a significantly higher WHR than other workers, their percentage of body fat did not appear to differ.

As mentioned, similar investigations have been limited to blue vs. white-collar occupational classifications only. Such previous systematic review evidence (that included self-report and device-measured outcomes) identified that white-collar workers (e.g. desk-based professionals) were more likely to engage in higher amounts of occupational ST and lower levels of occupational PA [20]. White-collar workers have also been shown engage in higher leisure-time PA compared to blue-collar workers [18]. We also found that office workers had higher occupational ST and lower occupational PA compared to blue-collar workers (e.g. laborers). Similar to our findings, higher step counts have been observed in blue-collar workers compared to white-collar workers [163]. Our finding that office workers had greater minutes of MVPA during wakeful time suggests that they are likely spending a greater amount of time engaged in non-work (e.g. travel, leisure) MVPA. However, given that evidence suggests a substantial amount (60-75 min) of daily MVPA is required to overcome large amounts of ST [162], office workers remain at health risk due to their high ST.

Adults who are employed in occupations with long work hours, stressful conditions and who engage in low levels of occupational PA are at the greatest risk for lower leisure-time PA $[18,164]$. Those participating in manual labor are more likely to engage in sedentary behaviour in their leisure-time, whereas office workers are less likely to engage in these behaviours in leisure-time [165]. Lunde et al. found that construction workers had a greater number of minutes/day of sitting in their leisure-time/outside of work than within (282 vs. 157 $\mathrm{min} /$ day) [94]. Mansoubi et al. found that office workers engaged in a greater proportion of MVPA and a lower proportion of ST outside of work hours than during [96].

Higher levels of occupational, leisure-time and total PA are shown to be associated with a reduced risk of all-cause mortality, especially among women [166]. Additionally, higher levels of occupational sitting have been associated with a greater risk for diabetes and mortality [9]. However, the "PA paradox" suggests that occupational PA may not 
confer the same benefits as leisure-time PA as it may: occur at too low of intensity; elevate BP as a result of heavy lifting and static postures; not provide adequate recovery time; and, be performed outside of a worker's control (e.g. work tasks, protective clothing, stressors, surrounding environment) [13, 167].

Globally, occupation-related energy expenditure and PA has decreased substantially since the 1960s and is projected to continue to decline [168-171]. Given that the majority of working adults' wakeful time is spent on the job, workplaces are opportune settings for PA. Previous research has shown that workplace interventions may increase MVPA, decrease ST and improve cardiometabolic health indicators among workers [172-176]. In addition, recent review evidence suggests that workplace interventions may improve mental health $[177,178]$, the ability to perform occupational tasks fully [179], and adverse musculoskeletal symptoms (e.g. neck and shoulder pain) [176, 180-182], though higher quality studies are still needed to identify the most promising interventions. Evidence has also shown that increasing PA levels may be advantageous to employers through reduced absenteeism [183, 184] and increased productivity [185]. The findings of this review therefore highlight the need for workplace and public health interventions to promote these behaviours both within and outside of work (i.e., active travel and leisure/recreation) and their cardiometabolic sequelae among working adults. It is also a call to action to recognize that more physically demanding occupations may not provide the same opportunity for health-enhancing PA. It is important that future research examines lower intensities of PA, the postural components of occupational work to understand the effects on health (e.g. prolonged standing, walking) and consider measuring sleep as part of the 24-h movement continuum.

Strengths of this review include a comprehensive search strategy developed with a research librarian (SV), an a priori established protocol with inclusion and exclusion criteria including device-measured movement intensities, cardiometabolic and fitness outcomes, the assessment of risk of bias, and the use of meta-analyses to provide overall summary measures across occupational groups. This review builds on previous research by focusing on device-measured outcomes, including varying intensities of PA and ST thereby removing sources of potential biases (recall and response bias). While device measures overcome biases, there was variation in the monitors used and cut-points/algorithms applied to determine intensity; we used a random effects model to account for such heterogeneity.

A limitation of this review is the small number of studies available for the meta-analyses of MPA, VPA, and the majority of the cardiometabolic outcomes. Further, there were insufficient studies to compare movement intensities across all specific occupations or occupational groups. There is a need for further studies to characterize the movement patterns (including comparisons between leisure- and work-specific movement and describing postural changes and bout duration of movement intensities) and cardiometabolic health and fitness in occupations, especially those that are not office workers. Future work would also benefit from examining the data in a more compositional manner looking at the 24-h daily period and how different behaviours at work might influence those outside. It is also important to recognize the limitations of many of the devices used which have the potential to misclassify behaviours. The cut-point thresholds employed, especially for the accelerometers, were often developed in controlled laboratory settings performing standard activities (e.g. walking on a treadmill) rather than during occupational tasks. This review included self-reported (largely BMI) and objectively measured cardiometabolic outcomes from studies which reported on the primary outcome of interest. Therefore, there is the potential for response bias. The meta-analytic software was unable to produce funnel plots and an Egger's test for the steps meta-analyses due to large standard deviations and small sample sizes (S. Tarlow [Comprehensive Meta-Analysis support], personal communication, August 20, 2018). We were unable to perform a sex-specific analysis as most studies did not report on male and female data separately. Our review did not examine any of the reasons for why PA and ST differed by occupation. However, research suggests that the differences are likely affected by an individual's work and leisure-time hours. During work hours, PA is most influenced by the type of tasks performed as part of the job, whereas, during leisure-time, socioeconomic background is an important determinant [186]. This is likely why there is a higher amount of leisure-time PA in white-collar workers. There was evidence of publication bias for many of the behaviour outcomes, as well as for body mass and BP, indicating that smaller studies had larger effect sizes. As most studies were smaller $(N<$ $100)$ and non-representative, there is a need for larger, more representative studies examining device-measured PA and ST in occupational groups. Lastly, wide confidence intervals for many of the outcomes are indicative of heterogeneity among several occupation groups within each analysis and thereby reduce our confidence in the estimates. Finally, it is likely that our categorizations have misclassified some studies into the wrong occupation group. For example, we included nurses, nurses' aides, physicians, diagnosticians and physiotherapists under healthcare workers. These groups may involve different types of work tasks. 


\section{Conclusion}

This review identified that work-based and wakeful PA and ST differed between occupations. Office workers spent the greatest amount of time at work and throughout wakeful time sedentary, but also spend the most minutes/ day in MVPA. Healthcare workers engage in more LPA, and laborers and postal delivery workers in more work time-specific MVPA. Future studies are needed to assess whether these patterns differ between men and women within the same occupation, describe leisure-time specific PA and ST and contrast them to occupational-specific PA and ST, and whether they translate to different levels of risk for poor cardiometabolic health. Ultimately, awareness that these health behaviours differ between occupations calls for the need to include workplace interventions that promote health-enhancing PA both at work and during leisure-time.

\section{Additional files}

\section{Additional file 1: Table S1. Sample Ovid MEDLINE search strategy.} (DOCX 24 kb)

Additional file 2: Table S2. Included study characteristics. (DOCX 82 kb) Additional file 3: Table S3. Physical behaviour outcomes by occupation group. (DOCX $100 \mathrm{~kb}$ )

Additional file 4: Figures S1-S18. Individual meta-analyses and funnel plots for behaviour, cardiometabolic and fitness outcomes. (PDF 658 kb)

Additional file 5: Table S4. Cardiometabolic and fitness outcomes by occupation group. (DOCX $54 \mathrm{~kb}$ )

\section{Acknowledgements}

We would like to thank Nicole Askin, MLIS (University of Manitoba Libraries, Winnipeg, MB) for peer review of our MEDLINE search strategy. We would also like to thank Dr. Kimberly Way for her advice regarding meta-analyses.

\section{Funding}

Dr. Stephanie Prince is funded by a Canadian Institutes of Health Research (CIHR) - Public Health Agency of Canada Health System Impact Fellowship. Dr. Jennifer Reed is funded, in part, by a CIHR New Investigator Salary Award.

\section{Availability of data and materials}

All data generated or analysed during this study are included in this published article [and its additional files].

\section{Authors' contributions}

SAP and JLR conceived of the study, SAP, CGE, SV and JLR designed the study, SAP, CGE, KS, and JLR screened the studies, and analyzed and interpreted the data. SAP performed the meta-analyses and led the writing of the paper, all authors edited and critically reviewed the manuscript, SAP had the primary responsibility for the final manuscript. All authors read and approved the final manuscript.

\section{Ethics approval and consent to participate}

Not applicable.

\section{Consent for publication}

Not applicable.

\section{Competing interests}

The authors declare that they have no competing interests.

\section{Publisher's Note}

Springer Nature remains neutral with regard to jurisdictional claims in published maps and institutional affiliations.

\section{Author details}

${ }^{1}$ Division of Cardiac Prevention and Rehabilitation, University of Ottawa Heart Institute, 40 Ruskin Street, Ottawa, Ontario K1Y 4W7, Canada. ${ }^{2}$ Centre for Surveillance and Applied Research, Public Health Agency of Canada, Ottawa, Canada. ${ }^{3}$ School of Human Kinetics, Faculty of Health Sciences, University of Ottawa, Ottawa, Canada. ${ }^{4}$ Berkman Library, University of Ottawa Heart Institute, Ottawa, Canada. ${ }^{5}$ School of Epidemiology and Public Health, Faculty of Medicine, University of Ottawa, Ottawa, Canada.

Received: 1 November 2018 Accepted: 8 March 2019

Published online: 02 April 2019

\section{References}

1. Warburton DER, Charlesworth S, Ivey A, Nettlefold L, Bredin SSD. A systematic review of the evidence for Canada's physical activity guidelines for adults. Int J Behav Nutr Phys Act. 2010;7:39.

2. Warburton DER, Bredin SSD. Health benefits of physical activity: a systematic review of current systematic reviews. Curr Op Cardiol. 2017;32(5):541-56.

3. World Health Organization. Information Sheet: global recommendations on physical activity for health 18-64 years. 2018. Available from: http://www.who. int/dietphysicalactivity/publications/recommendations18_64yearsold/en/.

4. Guthold RSG, Riley LM, Bull F. Worldwide trends in insufficient physical activity from 2001 to 2016: a pooled analysis of 358 population-based surveys with 1.9 million participants. Lancet. 2018; epub ahead of print.

5. Organization WH. Prevalence of insufficient physical activity. 2019. Available from: https://www.who.int/gho/ncd/risk_factors/physical_activity_text/en/.

6. Tremblay MS, Aubert S, Barnes JD, Saunders TJ, Carson V, Latimer-Cheung AE, et al. Sedentary behavior research network (SBRN) - terminology consensus project process and outcome. Int J Behav Nutr Phys Act. 2017;14(1):75.

7. Proper Kl, Singh AS, van Mechelen W, Chinapaw MJ. Sedentary behaviors and health outcomes among adults: a systematic review of prospective studies. Am J Prev Med. 2011;40(2):174-82.

8. Thorp AA, Owen N, Neuhaus M, Dunstan DW. Sedentary behaviors and subsequent health outcomes in adults a systematic review of longitudinal studies, 1996-2011. Am J Prev Med. 2011;41(2):207-15.

9. van Uffelen JG, Wong J, Chau JY, van der Ploeg HP, Riphagen I, Gilson ND et al. Occupational sitting and health risks: a systematic review. Am J Prev Med. 2010;39(4):379-88.

10. Biswas A, Oh PI, Faulkner GE, Bajaj RR, Silver MA, Mitchell MS, et al. Sedentary time and its association with risk for disease incidence, mortality, and hospitalization in adults: a systematic review and meta-analysis. Ann Intern Med. 2015;162(2):123-32.

11. Powell KE, King AC, Buchner DM, Campbell WW, DiPietro L, Erickson Kl, et al The scientific foundation for the physical activity guidelines for Americans, 2nd edition. J Phys Act Health. 2018:1-11.

12. Morris JN, Heady JA, Raffle PA, Roberts CG, Parks JW. Coronary heart-disease and physical activity of work. Lancet. 1953;265(6795):1053-7.

13. Holtermann A, Krause N, van der Beek AJ, Straker L. The physical activity paradox: six reasons why occupational physical activity (OPA) does not confer the cardiovascular health benefits that leisure time physical activity does. Br J Sports Med. 2018;52(3):149-50.

14. Reed $J \mathrm{~L}$, Prince SA, Pipe AL, Attallah S, Adamo KB, Tulloch HE, et al. Influence of the workplace on physical activity and cardiometabolic health: results of the multi-centre cross-sectional Champlain Nurses' study. Int J Nurs Stud. 2018;81: 49-60.

15. Coenen P, Huysmans MA, Holtermann A, Krause N, van Mechelen W, Straker LM, et al. Do highly physically active workers die early? A systematic review with meta-analysis of data from 193696 participants. Br J Sports Med. 2018; 52(20):1320-6.

16. Organization for Economic Co-operation and Development. Employment: time spent in paid and unpaid work, by sex. 2018 [5 Sept 2018]. Available from: https://stats.oecd.org/index.aspx?queryid=54757.

17. Howley ET. Type of activity- resistance, aerobic, and leisure vs. occupational physical activity. Med Sci Sports Exerc. 2001;33(6 Suppl):S364-9.

18. Kirk MA, Rhodes RE. Occupation correlates of adults' participation in leisuretime physical activity: a systematic review. Am J Prev Med. 2011;40(4):476-85. 
19. McCrady SK, Levine JA. Sedentariness at work: how much do we really sit? Obesity. 2009;17(11):2103-5.

20. Smith L, McCourt O, Sawyer A, Ucci M, Marmot A, Wardle J, et al. A review of occupational physical activity and sedentary behaviour correlates. Occup Med. 2016;66(3):185-92.

21. Prince SA, Adamo KB, Hamel ME, Hardt J, Connor Gorber S, Tremblay M. A comparison of direct versus self-report measures for assessing physical activity in adults: a systematic review. Int J Behav Nutr Phys Act. 2008;5:56.

22. Kwak L, Proper Kl, Hagstromer M, Sjostrom M. The repeatability and validity of questionnaires assessing occupational physical activity--a systematic review. Scand J Work Environ Health. 2011;37(1):6-29.

23. Colley RC, Butler G, Garriguet D, Prince SP, Roberts KC. Comparison of selfreported and accelerometer-measured physical activity in Canadian adults. Health Rep. 2018;29(12):3-15.

24. Kozey-Keadle S, Libertine A, Lyden K, Staudenmayer J, Freedson PS. Validation of wearable monitors for assessing sedentary behavior. Med Sci Sport Exerc. 2011:43(8):1561-7.

25. Plasqui G, Bonomi AG, Westerterp KR. Daily physical activity assessment with accelerometers: new insights and validation studies. Obes Rev. 2013;14(6):451-62.

26. The World Bank Group. High income. 2018. Available from: https://data. worldbank.org/income-level/high-income.

27. Sedgwick P, Marston L. How to read a funnel plot in a meta-analysis. BMJ. 2015;351:h4718.

28. Poitras VJ, Gray CE, Borghese MM, Carson V, Chaput JP, Janssen I, et al. Systematic review of the relationships between objectively measured physical activity and health indicators in school-aged children and youth. Appl Physiol Nutr Metab. 2016;41(6 Suppl 3):S197-239.

29. Abd T, Kobylivker A, Perry A, Miller lii J, Sperling L. Work-related physical activity among cardiovascular specialists. Clin Cardiol. 2012;35:78-82.

30. Alkhajah TA, Reeves MM, Eakin EG, Winkler EAH, Owen N, Healy GN. Sitstand workstations: a pilot intervention to reduce office sitting time. Am J Prev Med. 2012;43:298-303.

31. Andersen E, Hostmark AT, Lorentzen C, Anderssen SA. Low level of objectively measured physical activity and cardiorespiratory fitness, and high prevalence of metabolic syndrome among Pakistani male immigrants in Oslo, Norway. Norsk Epidemiol. 2011;20:199-208.

32. Arias OE, Caban-Martinez AJ, Umukoro PE, Okechukwu CA, Dennerlein JT. Physical activity levels at work and outside of work among commercial construction workers. J Occup Environ Med. 2015;57:73-8.

33. Arias OE, Umukoro PE, Stoffel SD, Hopcia K, Sorensen G, Dennerlein JT. Associations between trunk flexion and physical activity of patient care workers for a single shift: a pilot study. Work. 2017;56:247-55.

34. Atkinson J, Goody RB, Walker CA. Walking at work: a pedometer study assessing the activity levels of doctors. Scott Med J. 2005;50:73-5.

35. Badland HM, Schofield GM. The contribution of worksite physical activity to total daily-physical activity levels in professional occupations. N Z J Sports Med. 2004;32:48-54.

36. Balogh I, Orbaek P, Ohlsson K, Nordander C, Unge J, Winkel J, et al. Selfassessed and directly measured occupational physical activities--influence of musculoskeletal complaints, age and gender. Appl Ergon. 2004;35:49-56.

37. Bassey EJ, Patrick JM, Irving JM, Blecher A, Fentem PH. An unsupervised "aerobics" physical training programme in middle-aged factory workers: feasibility, validation and response. Eur J Appl Physiol Occup Physiol. 1983; 52:120-5.

38. Bird M-L, Shing C, Mainsbridge C, Cooley D, Pedersen S. Activity behaviors of university staff in the workplace: a pilot study. J Phys Act Health. 2015;12: 1128-32.

39. Brakenridge $C L$, Fjeldsoe BS, Young DC, Winkler EAH, Dunstan DW, Straker $L M$, et al. Evaluating the effectiveness of organisational-level strategies with or without an activity tracker to reduce office workers' sitting time: a cluster-randomised trial. Int J Behav Nutr Phys Act. 2016;13:115.

40. Brett CE, Pires-Yfantouda R. Enhancing participation in a national pedometerbased workplace intervention amongst staff at a Scottish university. Int J Health Promot Educ. 2017;55:215-28.

41. Brewer W, Ogbazi R, Ohl D, Daniels J, Ortiz A. A comparison of work-related physical activity levels between inpatient and outpatient physical therapists: an observational cohort trial. BMC Res Notes. 2016;9:313.

42. Brown HE, Ryde GC, Gilson ND, Burton NW, Brown WJ. Objectively measured sedentary behavior and physical activity in office employees: relationships with presenteeism. J Occup Environ Med. 2013;55:945-53.
43. Carr L, Swift M, Ferrer A, Benzo R. Cross-sectional examination of long-term access to sit-stand desks in a professional office setting. Am J Prev Med. 2016;50:96-100

44. Chae D, Kim S, Park $Y$, Hwang $Y$. The effects of an academic-workplace partnership intervention to promote physical activity in sedentary office workers. Workplace Health Saf. 2015;63:259-66.

45. Chappel SE, Aisbett B, Vincent GE, Ridgers ND. Firefighters' physical activity across multiple shifts of planned burn work. Int J Environ Res Public Health. 2016;13:973.

46. Chastin SFM, Dall PM, Tigbe WW, Grant MP, Ryan CG, Rafferty D, et al Compliance with physical activity guidelines in a group of UK-based postal workers using an objective monitoring technique. Eur J Appl Physiol. 2009;106:893-9.

47. Chau JY, Daley M, Dunn S, Srinivasan A, Do A, Bauman AE, et al. The effectiveness of sit-stand workstations for changing office workers' sitting time: results from the stand@work randomized controlled trial pilot. Int J Behav Nutr Phys Act. 2014;11:127.

48. Chau JY, Sukala W, Fedel K, Do A, Engelen L, Kingham M, et al. More standing and just as productive: effects of a sit-stand desk intervention on call center workers' sitting, standing, and productivity at work in the opt to stand pilot study. Prev Med Rep. 2016;3:68-74.

49. Cheung PPY, Chow BC, Parfitt G. Using environmental stimuli in physica activity intervention for school teachers: a pilot study. Int Elect J Health Educ. 2008;11:1-10.

50. Cheung PYP, Bik CC. Association of school teachers' occupational and daily physical activity level in Hong Kong. Int J Sport Health Sci. 2012;10:23-9.

51. Chitkara R. Characteristics of participants willing to enroll in a workplace based shared treadmill workstation study [M.Sc.]. Ann Arbor: University of Manitoba (Canada); 2014.

52. Choi S-W, Lee J-H, Jang Y-K, Kim J-R. Assessment of ambulatory activity in the Republic of Korea navy submarine crew. Undersea Hyperb Med. 2010; 37:413-7.

53. Clark BK, Thorp AA, Winkler EAH, Gardiner PA, Healy GN, Owen N, et al. Validity of self-reported measures of workplace sitting time and breaks in sitting time. Med Sci Sports Exerc. 2011;43:1907-12.

54. Clays E, Hallman D, Oakman J, Holtermann A. Objectively measured occupational physical activities in blue collar jobs: Do psychosocial resources matter? Eur J Prev Cardiol. 2017;24:20-1.

55. Clemes SA, Patel R, Mahon C, Griffiths PL. Sitting time and step counts in office workers. Occup Med. 2014;64:188-92.

56. Clemes SA, Oeconnell SE, Edwardson CL. Office workerse objectively measured sedentary behavior and physical activity during and outside working hours. J Occup Environ Med. 2014;56:298-303.

57. Cole JA, Tully MA, Cupples ME. "They should stay at their desk until the work's done": a qualitative study examining perceptions of sedentary behaviour in a desk-based occupational setting. BMC Res Notes. 2015;8:683.

58. Copeland D, Chambers M. Effects of unit design on acute care nurses' walking distances, energy expenditure, and job satisfaction: a pre-post relocation study. HERD. 2017;10:22-36.

59. Cuddy JS, Sol JA, Hailes WS, Ruby BC. Work patterns dictate energy demands and thermal strain during wildland firefighting. Wilderness Environ Med. 2015; 26:221-6.

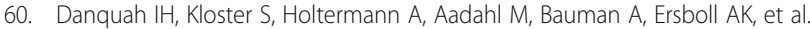
Take a stand!-a multi-component intervention aimed at reducing sitting time among office workers-a cluster randomized trial. Int J Epidemiol. 2017; 46:128-40.

61. Dollman J, Pontt JL, Rowlands AV. Validity of self-reported sedentary time differs between Australian rural men engaged in office and farming occupations. J Sports Sci. 2016;34:1154-8.

62. Donath L, Faude O, Schefer Y, Roth R, Zahner L. Repetitive daily point of choice prompts and occupational sit-stand transfers, concentration and neuromuscular performance in office workers: an RCT. Int J Environ Res Public Health. 2015;12:4340-53.

63. Evans RE, Fawole HO, Sheriff SA, Dall PM, Grant PM, Ryan CG. Point-ofchoice prompts to reduce sitting time at work: a randomized trial. Am J Prev Med. 2012;43:293-7.

64. Finkelstein EA, Sahasranaman A, John G, Haaland BA, Bilger M, Sloan RA, et al. Design and baseline characteristics of participants in the TRial of economic incentives to promote physical activity (TRIPPA): a randomized controlled trial of a six month pedometer program with financial incentives. Contemp Clin Trials. 2015;41:238-47. 
65. Foley B, Engelen L, Gale J, Bauman A, Mackey M. Sedentary behavior and musculoskeletal discomfort are reduced when office workers trial an activity-based work environment. J Occup Environ Med. 2016;58:924-31.

66. French SA, Harnack LJ, Toomey TL, Hannan PJ. Association between body weight, physical activity and food choices among metropolitan transit workers. Int J Behav Nutr Phys Act. 2007:4:52.

67. Gany F, Gill P, Baser R, Leng J. Supporting south Asian taxi drivers to exercise through pedometers (SSTEP) to decrease cardiovascular disease risk. J Urban Health. 2014;91:463-76.

68. Gao Y, Cronin NJ, Pesola AJ, Finni T. Muscle activity patterns and spinal shrinkage in office workers using a sit-stand workstation versus a sit workstation. Ergonomics. 2016;59:1267-74.

69. Gilson N, Ryde G. Walk@work-feasibility trial of an automated, website walking program for Australian office workers. J Sci Med Sport. 2010;13:e29-30.

70. Gilson, Faulker, Murphy, Meyer, Ryde, McCarthy, et al. Aninternational study of an automated web-based walking program (Walk@Work) to increase workday step counts in lower active office workers. J Sci Med Sport. 2012; 15:S235-S6.

71. Gilson ND, Suppini A, Ryde GC, Brown HE, Brown WJ. Does the use of standing 'hot' desks change sedentary work time in an open plan office? Prev Med. 2012;54:65-7.

72. Gilson ND, Ng N, Pavey TG, Ryde GC, Straker L, Brown WJ. Project energise: using participatory approaches and real time computer prompts to reduce occupational sitting and increase work time physical activity in office workers. J Sci Med Sport. 2016;19:926-30.

73. Gilson ND, Pavey TG, Wright OR, Vandelanotte C, Duncan MJ, Gomersall S, et al. The impact of an $\mathrm{m}$-health financial incentives program on the physical activity and diet of Australian truck drivers. BMC Public Health. 2017;17:467.

74. Gorman E, Ashe MC, Dunstan DW, Hanson HM, Madden K, Winkler EAH, et al. Does an 'activity-permissive' workplace change office workers' sitting and activity time? PLoS One. 2013;8:e76723.

75. Gram B, Westgate K, Karstad K, Holtermann A, Sogaard K, Brage S, et al. Occupational and leisure time physical activity and physical work load among construction workers. J Sci Med Sport. 2012;15:S308.

76. Gram B, Westgate K, Karstad K, Holtermann A, Søgaard K, Brage S, et al. Occupational and leisure-time physical activity and workload among construction workers - a randomized control study. Int J Occup Environ Health. 2016;22(1):36-44.

77. Hadgraft NT, Healy GN, Owen N, Winkler EAH, Lynch BM, Sethi $P$, et al. Office workers' objectively assessed total and prolonged sitting time: individual-level correlates and worksite variations. Prev Med Rep. 2016;4: 184-91.

78. Hallman DM, Birk Jørgensen M, Holtermann A. Objectively measured physical activity and 12-month trajectories of neck-shoulder pain in workers: a prospective study in DPHACTO. Scand J Public Health. 2017; 45:288-98.

79. He C. Physical and psychosocial demands on shift work in nursing homes [Ph.D.]. Ann Arbor: University of Cincinnati; 2013.

80. Healy GN, Eakin EG, Lamontagne AD, Owen N, Winkler EAH, Wiesner G, et al. Reducing sitting time in office workers: short-term efficacy of a multicomponent intervention. Prev Med. 2013;57:43-8.

81. Hogstedt Danquah I, Kloster S, Holtermann A, Aadahl M, Tolstrup JS. Effects on musculoskeletal pain from "take a stand!" - a cluster-randomized controlled trial reducing sitting time among office workers. Scand J Work Environ Health. 2017:43:350-7

82. James I, Smith A, Smith T, Kirby E, Press P, Doherty P. Randomized controlled trial of effectiveness of pedometers on general practitioners' attitudes to engagement in and promotion of physical activity. J Sports Sci. 2009;27:753-8.

83. Jancey JM, McGann S, Creagh R, Blackford KD, Howat P, Tye M. Workplace building design and office-based workers' activity: a study of a natural experiment. Aust N Z J Public Health. 2016;40:78-82.

84. Jirathananuwat A, Pongpirul K. Physical activity of nurse clinical practitioners and managers. J Phys Act Health. 2017;14:1-15.

85. Ju S, Wilbur J, Lee E, Miller A. Lifestyle physical activity behavior of Korean American dry cleaner couples. Public Health Nurs. 2011;28:503-14.

86. Julin M, Penttila H, Pesso K, Pekkanen H, Melin T, Rahijarvi P. Physical workload of construction workers in relation to their physical capacity. Physiotherapy. 2011;97:eS572.

87. Kirk AF, Knowles AM, Laverty K, Muggeridge D, Kelly L, Hughes A. Patterns of sedentary behaviour in office workers. Diabet Med. 2016;33:116.

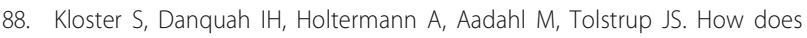
definition of minimum break length affect objective measures of sitting outcomes among office workers? J Phys Act Health. 2017;14:8-12.

89. Koepp GA, Manohar CU, McCrady-Spitzer SK, Ben-Ner A, Hamann DJ, Runge CF, et al. Treadmill desks: a 1-year prospective trial. Obesity. 2013:21:705-11.

90. Korshoj M, Krustrup P, Jespersen T, Sogaard K, Skotte JH, Holtermann A. A 24-h assessment of physical activity and cardio-respiratory fitness among female hospital cleaners: a pilot study. Ergonomics. 2013;56:935-43.

91. Kozey-Keadle S, Libertine A, Staudenmayer J, Freedson P. The feasibility of reducing and measuring sedentary time among overweight, non-exercising office workers. J Obes. 2012;2012:282303.

92. Lagersted-Olsen J, Korshoj M, Skotte J, Carneiro IG, Sogaard K, Holtermann A. Comparison of objectively measured and self-reported time spent sitting. Int J Sports Med. 2014;35:534-40

93. Li I, Mackey MG, Foley B, Pappas E, Edwards K, Chau JY, et al. Reducing office workers' sitting time at work using sit-stand protocols: results from a pilot randomized controlled trial. J Occup Environ Med. 2017;59:543-9.

94. Lunde LK, Koch M, Knardahl S, Veiersted KB. Associations of objectively measured sitting and standing with low-back pain intensity: a 6-month follow-up of construction and healthcare workers. Scand J Work Environ Health. 2017:43:269-78.

95. Mansi S, Milosavljevic S, Tumilty S, Hendrick P, Higgs C, Baxter DG. Investigating the effect of a 3-month workplace-based pedometer-driven walking programme on health-related quality of life in meat processing workers: a feasibility study within a randomized controlled trial. BMC Public Health. 2015;15:410.

96. Mansoubi M, Pearson N, Biddle SJH, Clemes SA. Using sit-to-stand workstations in offices: is there a compensation effect? Med Sci Sports Exerc. 2016;48:720-5.

97. Martinez de Tejada B, Jastrow N, Poncet A, Le Scouezec I, Irion O, Kayser B. Perceived and measured physical activity and mental stress levels in obstetricians. Eur J Obstet Gynecol Reprod Biol. 2013;171:44-8.

98. Miller R, Brown W. Steps and sitting in a working population. Int J Behav Med. 2004;11:219-24.

99. Mitsui T, Barajima T, Kanachi M, Shimaoka K. Daily walking activity among male office workers in a rural town in northern Japan. J Physiol Anthropol. 2010;29:43-6.

100. Murphy IG, Murphy CG, Heffernan EJ. A comparative analysis of the occupational energy expenditure of radiologists versus clinicians. Ir J Med Sci. 2015;184:889-92.

101. Neil-Sztramko SE, Ghayyur A, Edwards J, Campbell KL. Physical activity levels of physiotherapists across practice settings: a cross-sectional comparison using self-report questionnaire and accelerometer measures. Physiother Can. 2017;69:152-60

102. Neuhaus M, Healy GN, Dunstan DW, Owen N, Eakin EG. Workplace sitting and height-adjustable workstations: a randomized controlled trial. Am J Prev Med. 2014;46:30-40.

103. Parry S, Straker L, Gilson ND, Smith AJ. Participatory workplace interventions can reduce sedentary time for office workers--a randomised controlled trial. PLoS One. 2013;8:e78957.

104. Parry S, Straker L. The contribution of office work to sedentary behaviour associated risk. BMC Public Health. 2013;13:296.

105. Peavler M. Worksite intervention to reduce sedentary time [M.S.]. Ann Arbor: East Carolina University; 2012.

106. Pedersen ESL, Danquah $\|_{\text {, Petersen } C B}$, Tolstrup JS. Intra-individual variability in day-to-day and month-to-month measurements of physical activity and sedentary behaviour at work and in leisure-time among Danish adults. BMC Public Health. 2016;16:1222

107. Pontt JL, Rowlands AV, Dollman J. Comparison of sedentary behaviours among rural men working in offices and on farms. Aus J Rur Health. 2015;23:74-9.

108. Reed JL, Cole CA, Ziss MC, Tulloch HE, Brunet J, Sherrard H, et al. The impact of web-based feedback on physical activity and cardiovascular health of nurses working in a cardiovascular setting: a randomized trial. Front Physiol. 2018;9:142.

109. Ryan CG, Grant PM, Dall PM, Granat MH. Sitting patterns at work: objective measurement of adherence to current recommendations. Ergonomics. 2011;54:531-8.

110. Ryde GC, Brown HE, Peeters GMEE, Gilson ND, Brown WJ. Desk-based occupational sitting patterns: weight-related health outcomes. Am J Prev Med. 2013;45:448-52. 
111. Sawyer A, Smith L, Ucci M, Jones R, Marmot A, Fisher A. Perceived office environments and occupational physical activity in office-based workers. Occup Med. 2017;67:260-7

112. Schnebly KL. Ten-thousand step challenge for bedside nurses working 12hour shifts [D.N.P.]. Ann Arbor: Walden University; 2017.

113. Schofield G, Badlands $H$, Oliver M. Objectively-measured physical activity in New Zealand workers. J Sci Med Sport. 2005:8:143-51.

114. Smith SL, McNie CM, Duddy SM, Goldsmith AAJ, Bennett D, Orr JF, et al. Demographic and occupational effects on the activity levels of normal subjects in the United Kingdom. Hip Int. 2002;12:28-36.

115. Smith L, Hamer M, Ucci M, Marmot A, Gardner B, Sawyer A, et al. Weekday and weekend patterns of objectively measured sitting, standing, and stepping in a sample of office-based workers: the active buildings study. BMC Public Health. 2015;15:9.

116. Soh M, Deam RK, Kluger R. 10,000 reasons to step out--exercise patterns and pedometer evaluation of consultant anaesthetists. Anaesth Intensive Care. 2006;34:347-52.

117. Steeves JA, Tudor-Locke C, Murphy RA, King GA, Fitzhugh EC, Harris TB. Classification of occupational activity categories using accelerometry: NHANES 2003-2004. Int J Behav Nutr Phys Act. 2015;12:89.

118. Straker L, Abbott RA, Heiden M, Mathiassen SE, Toomingas A. Sit-stand desks in call centres: associations of use and ergonomics awareness with sedentary behavior. Appl Ergon. 2013;44:517-22.

119. Swartz AM, Rote AE, Welch WA, Maeda H, Hart TL, Cho Yl, et al. Prompts to disrupt sitting time and increase physical activity at work, 2011-2012. Prev Chron Dis. 2014;11:E73.

120. Talbot LA, Metter EJ, Morrell CH, Frick KD, Weinstein AA, Fleg JL. A pedometerbased intervention to improve physical activity, fitness, and coronary heart disease risk in National Guard personnel. Mil Med. 2011;176:592-600.

121. Thorp AA, Healy GN, Winkler E, Clark BK, Gardiner PA, Owen N, et al. Prolonged sedentary time and physical activity in workplace and non-work contexts: a cross-sectional study of office, customer service and call centre employees. Int J Behav Nutr Phys Act. 2012;9:128.

122. Tigbe WW, Lean MEJ, Granat MH. A physically active occupation does not result in compensatory inactivity during out-of-work hours. Prev Med. 2011;53:48-52.

123. Tobin R, Leavy J, Jancey J. Uprising: an examination of sit-stand workstations, mental health and work ability in sedentary office workers, in Western Australia. Work. 2016:55:359-71.

124. Toomingas A, Forsman M, Mathiassen SE, Heiden M, Nilsson T. Variation between seated and standing/walking postures among male and female call centre operators. BMC Public Health. 2012;12:154.

125. Umukoro PE, Arias OE, Stoffel SD, Hopcia K, Sorensen G, Dennerlein JT. Physical activity at work contributes little to patient care workerse weekly totals. J Occup Environ Med. 2013;55:S63-S8.

126. Urda JL, Lynn JS, Gorman A, Larouere B. Effects of a minimal workplace intervention to reduce sedentary behaviors and improve perceived wellness in middle-aged women office workers. J Phys Act Health. 2016;13:838-44.

127. van Dommelen $P$, Coffeng JK, van der Ploeg HP, van der Beek AJ, Boot CRL, Hendriksen IJM. Objectively measured total and occupational sedentary time in three work settings. PLoS One. 2016;11:e0149951.

128. Veronica Varela Mato V, O'Shea O, King J, Yates T, Stensel DJ, Biddle SJ, et al. Lorry driver's cardiovascular health, physical activity and sedentary behaviours-phase 1 of the shift study NIHR Leicester-Lough borough diet, lifestyle and physical activity biomedical research unit. Eur J Prev Cardiol. 2016:23:S62

129. Varela-Mato V, Yates T, Stensel DJ, Biddle SJH, Clemes SA. Time spent sitting during and outside working hours in bus drivers: a pilot study. Prev Med Rep. 2016;3:36-9.

130. Varela Mato V, Yates T, Stensel D, Biddle S, Clemes SA. Concurrent validity of actigraph-determined sedentary time against the activpal under free-living conditions in a sample of bus drivers. Meas Phys Educ Exerc Sci. 2017:4:1-11.

131. Varela-Mato V, O'Shea O, King JA, Yates T, Stensel DJ, Biddle SJ, et al. Crosssectional surveillance study to phenotype lorry drivers' sedentary behaviours, physical activity and cardio-metabolic health. BMJ Open. 2017;7:e013162.

132. Vincent GE, Ridgers ND, Ferguson SA, Aisbett B. Associations between firefighters' physical activity across multiple shifts of wildfire suppression. Ergonomics. 2016:59:924-31

133. Waters CN, Ling EP, Chu AHY, Ng SHX, Chia A, Lim YW, et al. Assessing and understanding sedentary behaviour in office-based working adults: a mixedmethod approach. BMC Public Health. 2016;16:360.
134. Weiler R, Aggio D, Hamer M, Taylor T, Kumar B. Sedentary behaviour among elite professional footballers: health and performance implications. BMJ Open Sport Exerc Med. 2015;1:e000023.

135. Wieters KM. Integrating walking for transportation and physical activity for sedentary office workers in Texas. Ann Arbor: Texas A\&M University; 2009.

136. Wong JYL, Gilson ND, Bush RA, Brown WJ. Patterns and perceptions of physical activity and sedentary time in male transport drivers working in regional Australia. Aus N Z J Public Health. 2014;38:314-20.

137. Ying H, Eunhwa Y. Building spatial layout that supports healthier behavior of office workers: a new performance mandate for sustainable buildings. Work. 2014;49:373-80.

138. Aandstad A, Hageberg R, Holme IM, Anderssen SA. Objectively measured physical activity in home guard soldiers during military service and civilian life. Mil Med. 2016;181(7):693-700.

139. Arundell L, Sudholz B, Teychenne M, Salmon J, Hayward B, Healy GN, et al. The impact of activity based working (ABW) on workplace activity, eating behaviours, productivity, and satisfaction. Int J Environ Res Public Health. 2018;15(5). https://doi.org/10.3390/ijerph15051005.

140. Bergman F, Wahlstrom V, Stomby A, Otten J, Lanthen E, Renklint R, et al. Treadmill workstations in office workers who are overweight or obese: a randomised controlled trial. Lancet Public Health. 2018;3(11):e523-e35.

141. Chan L, McNaughton H, Weatherall M. Are physical activity levels of health care professionals consistent with activity guidelines? A prospective cohort study in New Zealand. JRSM Cardiovasc Dis. 2018;7:2048004017749015.

142. Croteau KA. Using pedometers to increase the non-workday steps of hospital nursing and support staff: a pilot study. Workplace Health Saf. 2017; 65(10):452-6.

143. De Jong NP, Debache I, Pan Z, Garnotel M, Lyden K, Sueur C, et al. Breaking up sedentary time in overweight/obese adults on work days and non-work days: results from a feasibility study. Int J Environ Res Public Health. 2018; 15(11):2566.

144. Fisher A, Ucci M, Smith L, Sawyer A, Spinney R, Konstantatou M, et al. Associations between the objectively measured office environment and workplace step count and sitting time: cross-sectional analyses from the active buildings study. Int J Environ Res Public Health. 2018;15(6):1135.

145. Hallman DM, Mathiassen SE, Jahncke $H$. Sitting patterns after relocation to activity-based offices: a controlled study of a natural intervention. Prev Med. 2018;111:384-90.

146. Healy GN, Eakin EG, Owen N, Lamontagne AD, Moodie M, Winkler EA, et al. A cluster randomized controlled trial to reduce office workers' sitting time: effect on activity outcomes. Med Sci Sports Exerc. 2016;48(9):1787-97.

147. Larouche M. Feasibility of using prompts to reduce sedentary behavior in office workers with sit-stand workstations: a randomized cross-over trial. Ann Arbor: Arizona State University; 2018.

148. Loef B, Van Der Beek AJ, Holtermann A, Hulsegge G, Van Baarle D, Proper KI. Objectively measured physical activity of hospital shift workers. Scand J Work Environ Health. 2018:44(3):265-73.

149. Nooijen CFJ, Kallings LV, Blom V, Ekblom O, Forsell Y, Ekblom MM. Common perceived barriers and facilitators for reducing sedentary behaviour among office workers. Int J Environ Res Public Health. 2018;15(4):E792.

150. Olsen HM, Brown WJ, Kolbe-Alexander T, Burton NW. A brief self-directed intervention to reduce office employees' sedentary behavior in a flexible workplace. J Occup Environ Med. 2018:60(10):954-9.

151. Pedersen SJ, Kitic CM, Bird M-L, Mainsbridge CP, Cooley PD. Is self-reporting workplace activity worthwhile? Validity and reliability of occupational sitting and physical activity questionnaire in desk-based workers. BMC Public Health. 2016;16(1):836

152. Rafferty D, Dolan C, Granat M. Attending a workplace: its contribution to volume and intensity of physical activity. Physiol Meas. 2016;37(12):2144-53.

153. Schulz PS, Zimmerman L, Johansson P. Seasonal work and cardiovascular risk factors in farmers. J Cardiovasc Nur. 2018;33(4):E35-E9.

154. Schwartz J, Bredin SSD, Oh P, Hansen B, Hives B, Buckler EJ, et al. Physical activity levels at a sedentary workplace in Canada's fittest province. J Cardiopulm Rehabil Prev. 2016;36(5):388.

155. Steeves JA, Tudor-Locke C, Murphy RA, King GA, Fitzhugh EC, Bassett DR, et al. Daily physical activity by occupational classification in us adults: NHANES 2005-2006. J Phys Act Health. 2018;15:1-12.

156. Stephens SK, Eakin EG, Clark BK, Winkler EAH, Owen N, Lamontagne AD, et al. What strategies do desk-based workers choose to reduce sitting time and how well do they work? Findings from a cluster randomised controlled trial. Int J Behav Nutr Phys Act. 2018;15:98. 
157. Sudholz B, Ridgers ND, Mussap A, Bennie J, Timperio A, Salmon J. Reliability and validity of self-reported sitting and breaks from sitting in the workplace. J Sci Med Sport. 2018;21(7):697-701.

158. Taylor WC, Paxton RJ, Shegog R, Coan SP, Dubin A, Page TF, et al. Impact of booster breaks and computer prompts on physical activity and sedentary behavior among desk-based workers: a cluster-randomized controlled trial. Prev Chronic Dis. 2016;13:E155.

159. Torquati L, Kolbe-Alexander T, Pavey T, Leveritt M. Changing diet and physical activity in nurses: a pilot study and process evaluation highlighting challenges in workplace health promotion. J Nutr Educ Behav. 2018;50(10): 1015-25.

160. Zhu W, Gutierrez M, Toledo MJ, Mullane S, Stella AP, Diemar R, et al. Longterm effects of sit-stand workstations on workplace sitting: a natural experiment. J Sci Med Sport. 2018;21(8):811-6.

161. Tudor-Locke C, Craig CL, Brown WJ, Clemes SA, De Cocker K, Giles-Corti B, et al. How many steps/day are enough? For adults. Int J Behav Nutr Phys Act. 2011;8:79.

162. Ekelund U, Steene-Johannessen J, Brown WJ, Fagerland MW, Owen N, Powell KE, et al. Does physical activity attenuate, or even eliminate, the detrimental association of sitting time with mortality? A harmonised metaanalysis of data from more than 1 million men and women. Lancet. 2016; 388(10051):1302-10

163. Steele R. Occupational physical activity across occupational categories. J Sci Med Sport. 2003;6(4):398-407.

164. Trost SG, Owen N, Bauman AE, Sallis JF, Brown W. Correlates of adults' participation in physical activity: review and update. Med Sci Sports Exerc. 2002;34(12):1996-2001.

165. O'Donoghue G, Perchoux C, Mensah K, Lakerveld J, van der Ploeg H, Bernaards $C$, et al. A systematic review of correlates of sedentary behaviour in adults aged 18-65 years: a socio-ecological approach. BMC Public Health. 2016; 16:163.

166. Samitz G, Egger M, Zwahlen M. Domains of physical activity and all-cause mortality: systematic review and dose-response meta-analysis of cohort studies. Int J Epidemiol. 2011;40(5):1382-400,

167. Holtermann A, Hansen J, Burr H, Søgaard K, Sjøgaard G. The health paradox of occupational and leisure-time physical activity. Br J Sports Med. 2011;46: bjsports79582

168. Church TS, Thomas DM, Tudor-Locke C, Katzmarzyk PT, Earnest CP, Rodarte $R Q$, et al. Trends over 5 decades in U.S. occupation-related physical activity and their associations with obesity. PLoS One. 2011;6(5):e19657.

169. Brownson RC, Boehmer TK, Luke DA. Declining rates of physical activity in the United States: what are the contributors? Ann Rev Public Health. 2005; 26(1):421-43.

170. Ng SW, Popkin B. Time use and physical activity: a shift away from movement across the globe. Obes Rev. 2012;13(8):659-80.

171. Hallal PC, Andersen LB, Bull FC, Guthold R, Haskell W, Ekelund U. Global physical activity levels: surveillance progress, pitfalls, and prospects. Lancet. 2012;380(9838):247-57.

172. Reed JL, Prince SA, Elliott CG, Mullen KA, Tulloch HE, Hiremath S, et al. Impact of workplace physical activity interventions on physical activity and cardiometabolic health among working-age women: a systematic review and meta-analysis. Circ Cardiovasc Qual Outcomes. 2017;10(2). https://doi. org/10.1161/CIRCOUTCOMES.116.003516.

173. Malik SH, Blake H, Suggs LS. A systematic review of workplace health promotion interventions for increasing physical activity. Br J Health Psychol. 2014;19(1):149-80.

174. Shrestha N, Kukkonen-Harjula KT, Verbeek JH, ljaz S, Hermans V, Pedisic Z. Workplace interventions for reducing sitting at work. Cochrane Database Sys Rev. 2018;6:Cd010912.

175. Tam G, Yeung MPS. A systematic review of the long-term effectiveness of work-based lifestyle interventions to tackle overweight and obesity. Prev Med. 2018;107:54-60.

176. Proper KI, Koning M, van der Beek AJ, Hildebrandt VH, Bosscher RJ, van Mechelen $\mathrm{W}$. The effectiveness of worksite physical activity programs on physical activity, physical fitness, and health. Clin J Sport Med. 2003;13(2): 106-17.

177. Abdin S, Welch RK, Byron-Daniel J, Meyrick J. The effectiveness of physical activity interventions in improving well-being across office-based workplace settings: a systematic review. Public Health. 2018;160:70-6.
178. Chu AH, Koh D, Moy FM, Muller-Riemenschneider F. Do workplace physical activity interventions improve mental health outcomes? Occup Med. 2014; 64(4):235-45.

179. Oakman J, Neupane S, Proper Kl, Kinsman N, Nygard CH. Workplace interventions to improve work ability: a systematic review and meta-analysis of their effectiveness. Scand J Work Environ Health. 2018;44(2):134-46.

180. Chen X, Coombes BK, Sjogaard G, Jun D, O'Leary S, Johnston V. Workplacebased interventions for neck pain in office workers: systematic review and meta-analysis. Phys Ther. 2018;98(1):40-62.

181. Lowry V, Desjardins-Charbonneau A, Roy JS, Dionne CE, Fremont P, MacDermid

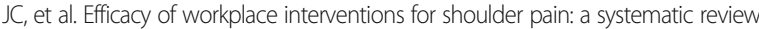
and meta-analysis. J Rehabil Med. 2017;49(7):529-42.

182. Fimland MS, Vie G, Holtermann A, Krokstad S, Nilsen TIL. Occupational and leisure-time physical activity and risk of disability pension: prospective data from the HUNT Study, Norway. Occup Environ Med. 2018;75(1):23-8.

183. Robroek SJW, van den Berg TIJ, Plat JF, Burdorf A. The role of obesity and lifestyle behaviours in a productive workforce. Occup Environ Med. 2011; 68(2):134-9.

184. Losina E, Yang HY, Deshpande BR, Katz JN, Collins JE. Physical activity and unplanned illness-related work absenteeism: data from an employee wellness program. PLoS One. 2017;12(5):e0176872.

185. Pereira MJ, Coombes BK, Comans TA, Johnston V. The impact of onsite workplace health-enhancing physical activity interventions on worker productivity: a systematic review. Occup Environ Med. 2015;72(6):401-12.

186. Stalsberg R, Pedersen AV. Are differences in physical activity across socioeconomic groups associated with choice of physical activity variables to report? Int J Environ Res Public Health. 2018;15(5):922.

\section{Ready to submit your research? Choose BMC and benefit from:}

- fast, convenient online submission

- thorough peer review by experienced researchers in your field

- rapid publication on acceptance

- support for research data, including large and complex data types

- gold Open Access which fosters wider collaboration and increased citations

- maximum visibility for your research: over $100 \mathrm{M}$ website views per year

At BMC, research is always in progress.

Learn more biomedcentral.com/submissions 